\title{
REVIEW
}

\section{Effect of breast milk and weaning on epithelial growth of the small intestine in humans}

\section{A G Cummins, F M Thompson}

Gut 2002;51:748-754

Breast feeding and weaning are important physiologically significant luminal events that influence the growth of the small intestine in humans. A variety of factors including genetic preprogramming, systemic and local hormones, and permissive factors contribute and modulate intestinal growth. Here, we offer a view that integrates some of these factors, especially those relating to breast feeding and weaning.
See end of article for authors' affiliations

...................

Dr A G Cummins, Department of Gastroenterology and Hepatology, DX 465384 The Queen Elizabeth Hospital, Woodville South, SA 5011, Australia;

adrian.cummins@ nwahs.sa.gov.au

Accepted for publication 18 January 2002

\section{SUMMARY}

Both breast feeding and weaning are important physiologically significant luminal events that influence the growth of the small intestine in humans. A variety of other factors such as genetic preprogramming, systemic and local hormones, and permissive factors contribute and modulate intestinal growth. The epithelium in the neonate has narrow finger-like villi and small crypts. Expansion of the epithelial surface of the small intestine occurs by crypt fission (in which crypts unzip and duplicate themselves) and by crypt hyperplasia. These are independent processes that expand the number of crypts and villi and increase the surface area of individual villi. Breast fed infants have smaller villi and crypts than bottle fed infants, suggesting that crypt fission may be the predominant mechanism of epithelial growth during milk feeding whereas crypt hyperplasia predominates later during weaning (2-6 months of age). Presumably growth factor(s) in breast milk or others produced endogenously interact with specific mucosal growth factor receptors in the neonatal gut. In addition, breast milk may contain inhibitory growth factor(s) for crypt hyperplasia. Epithelial crypt hyperplasia may be promoted by physiological inflammation of the gut associated lymphoid tissue that peaks during infancy from antigenic stimulation of weaning. Expansion of the intestinal surface area during weaning would help to accommodate the nutrient load. Conversely, experimental immunosuppression in animals during infancy retards epithelial growth.

\section{INTRODUCTION}

A variety of factors have been suggested to control epithelial growth of the small intestine including: genetic preprogramming; growth factors in breast milk; drive from luminal factors such as food, bile, and pancreatic secretions; endocrine effects of hormones such as corticosteroids, growth hormone, and insulin, or the paracrine effects of local growth factors; effects mediated via the systemic and/or enteric nervous system; and effects mediated by the gut associated lymphoid tissue. ${ }^{1-6}$ Progress has been slow except for understanding intestinal morphogenesis. Our purpose here is to offer a view that integrates some of these factors, especially those relating to breast feeding and weaning. The focus is principally on intestinal growth in humans although animal data are also considered.

Studies of growth of the small intestine have been principally undertaken in vitro or in experimental animals with only occasional investigation of human intestinal development. Human studies have reported fetal development ${ }^{7}$ and postnatal growth. ${ }^{8-10}$ Differences between humans and other species make comparison of intestinal growth difficult. Few studies have examined growth appropriately by quantitative histological techniques. In recent times, the use of paediatric endoscopy has provided the opportunity of taking biopsies safely from the duodenum to study human intestinal growth postnatally. In particular it is possible to study the effect of breast milk and of weaning on epithelial growth of the small intestine in humans as these two factors are major physiological events in the infant that alter luminal contents.

\section{EPITHELIAL GROWTH DURING MILK FEEDING \\ Epithelial growth with crypt fission and expansion of the primary mucosal surface} At birth, the human neonate has predominantly narrow finger-like villi and small crypts. ${ }^{8}{ }^{11-13}$ The pattern of intestinal growth both during fetal life and continuing postnatally is binary fission (duplication) of intestinal crypts, as observed in neonatal rats and a human infant. ${ }^{14-16}$ This is associated with cylindrical growth of the small intestine (fig 1). The length of the small intestine at term, one, five, and 20 years is $275,380,450$, and $575 \mathrm{~cm}$, respectively. During crypt fission, small indentations are seen at the base of a crypt which gradually divide (unzip) the crypt longitudinally into two daughter crypts. In rats at least, crypt fission reduces from $30-45 \%$ of crypts during milk feeding to about $3-7 \%$ of crypts after weaning. ${ }^{15}$ We have evaluated crypt fission in duodenal biopsies taken during endoscopy of

Abbreviations: EGF, epidermal growth factor; $\mathrm{GH}$ growth hormone; KGF, keratinocyte growth factor; IGF-1, insulin-like growth factor 1; Epo, erythropoietin; GLP, glucagon-like polypeptide; TGF, transforming growth factor; HGF, hepatocyte growth factor. 
Cylindrical growth of the small intestine

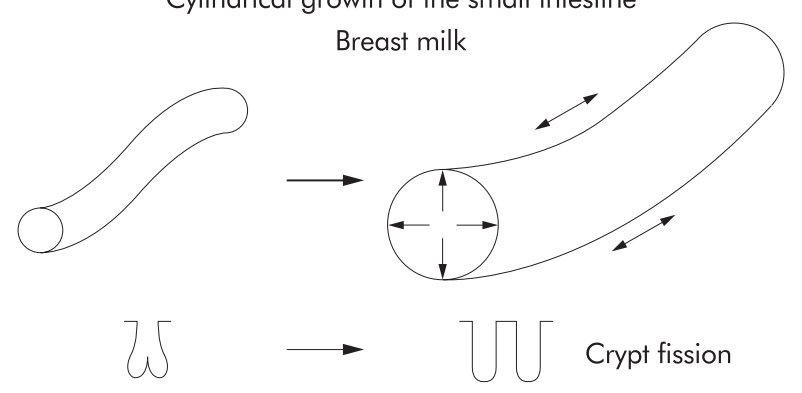

Luminal growth of the small intestine

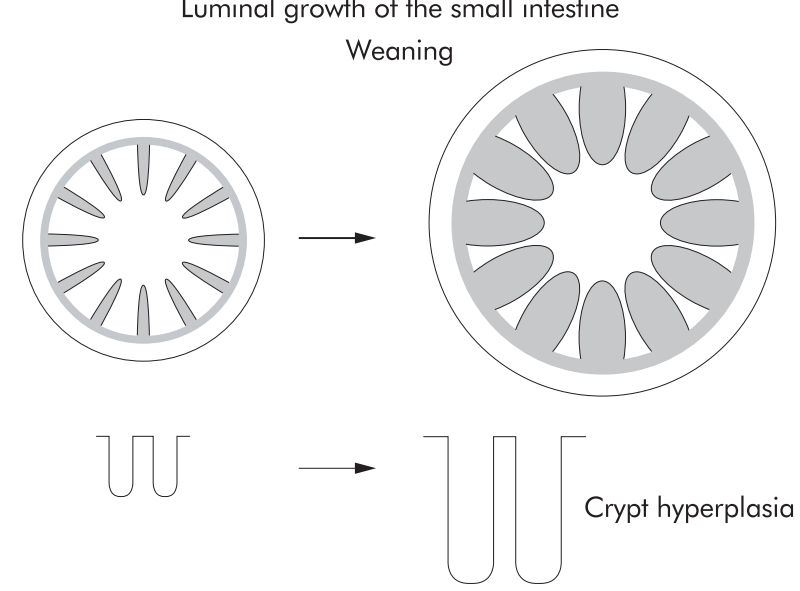

Figure 1 The small intestine has two patterns of growth. Firstly, there is cylindrical organ growth in length and diameter, and secondly, there is luminal mucosal growth with amplification of the internal surface area by submucosal folds and villi.

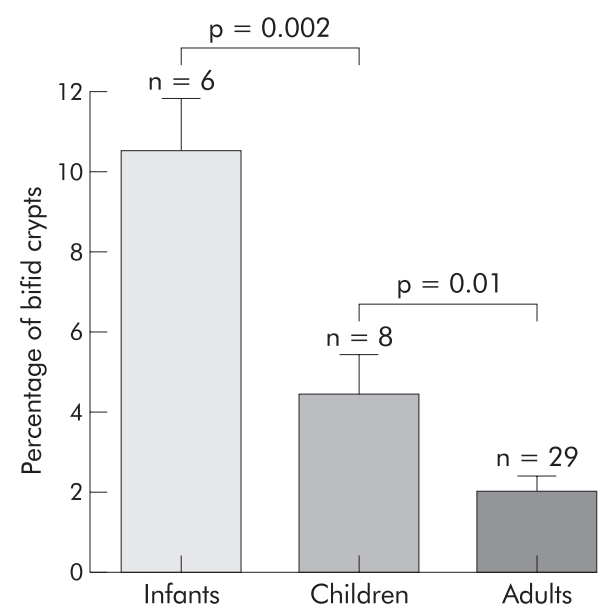

Figure 2 Intestinal crypt fission in human infants, children, and adults. Data are given as mean (SEM) ( $\mathrm{n}=$ number of subjects). Means of groups were compared using Peritz' F test.

infants and children being investigated for reflux oesophagitis and have found that the mean percentage of crypt fission in infants (aged less than two years), children (2-10 years), and adults is $10.2 \%, 4.4 \%$, and $2.0 \%$, respectively (fig 2 ).

Presumably, crypt fission is promoted by a growth factor, although none has been identified so far. Epidermal growth factor (EGF), growth hormone (GH), and keratinocyte growth factor (KGF) decrease crypt fission in the small intestine or colon during repair but promote crypt hyperplasia. ${ }^{17-19}$ As the action of GH is mediated by insulin-like growth factor 1 (IGF$1)$, it is likely that IGF-1 also reduces crypt fission. Other lig-

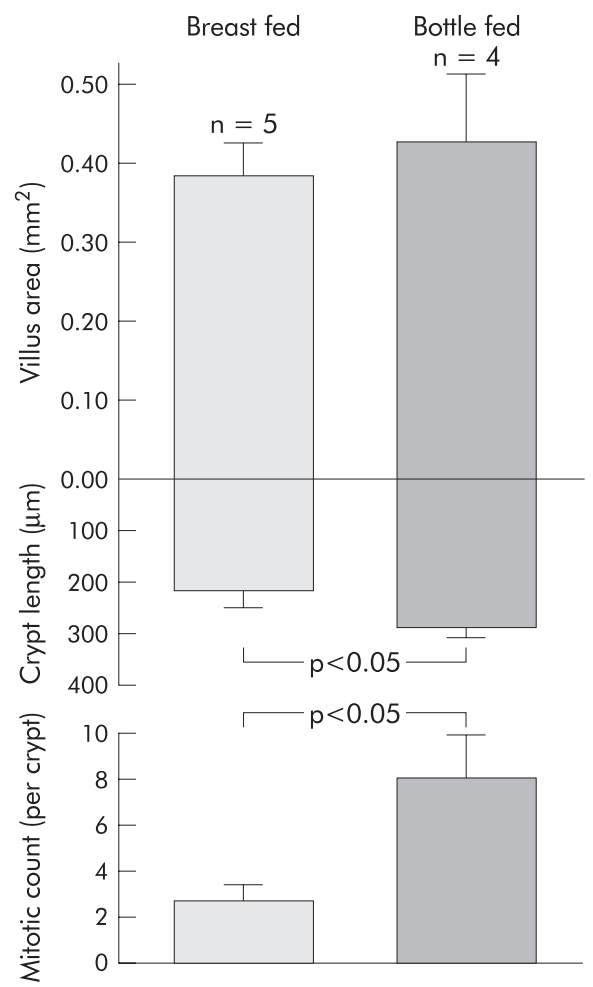

Figure 3 Intestinal morphometry in infants of 2-6 months of age who were entirely breast fed compared with those who were bottle fed. Graphs were drawn from a study by Thompson and colleagues. ${ }^{38}$

ands (amphiregulin, betacellulin, cripto, epiregulin, heparin binding EGF, heregulin, transforming growth factor (TGF)- $\alpha$ ) of the EGF receptor would be expected to also reduce crypt fission. Presumably, crypt fission is mediated by factors in breast milk or endogenously produced growth factors acting on specific growth factor receptors that are present at this age.

Milk borne growth factors for the small intestine

The small intestine of animals grows rapidly during early suckling compared with littermates that are either not suckled or fed artificially. ${ }^{20-24}$ These studies showed that breast milk contains growth factor(s) that stimulate intestinal growth postnatally. Unfortunately, these studies did not examine the morphological response of the mucosa-that is, whether there was bifid division of intestinal crypts versus crypt hyperplasia. Our study has indicated that breast fed infants have smaller crypts than bottle fed infants and indicates that growth does not occur predominantly by crypt hyperplasia (fig 3 ).

\section{Assessing the physiological relevance of potential growth factors in breast milk}

One way to investigate the physiological significance of milk borne growth factors is to assess the presence and activation of growth factor receptors in the human neonatal and infant intestine during breast feeding. These receptors include c-met (hepatocyte growth factor (HGF) receptor), erythropoietin (Epo) receptor, EGF receptor, glucagon-like polypeptide (GLP)-2 receptor, IGF-1 receptor, and KGF receptor (see table 1). The working hypothesis is that breast milk contains potential growth factors that act via their relevant receptors in the small intestine and that these receptors are physiologically upregulated during this period of growth and therefore intrinsically programmed at this age. It is likely that upregulation of some, if not all, of these specific growth factor receptors is present in bottle fed infants. As intestinal permeability is increased in bottle fed infants, one could speculate as to 
Table 1 Comparison of various growth factors for the small intestine. The first column lists whether the growth factor has increased levels/activity in the mucosa during intestinal growth, the second lists the effect of pharmacological doses (or transgenically) of the growth factor in vivo, the third lists the effect of the growth factor in cell or explant culture, and the fourth column lists the effect of ablation, blockade, or state of intestinal development in the growth factor or the corresponding receptor knockout mouse

\begin{tabular}{lllll}
\hline Growth factor & Growth factor activity & Pharmacological action & In vitro effect & Blockade \\
\hline Corticosteroids* & No & Antitrophic & Yes & Yes \\
EGF & Present in milk & Yes & Yes & Yes, KO \\
Epo & Present in milk & Yes & Yes & Lethal KO \\
bFGF & ND & Yes & Yes & Yes \\
GH & ND & Yes & ND & Yes \\
GLP-2† & ND & Yes & ND & ND \\
HGF & Present in milk & Yes & Yes & Lethal KO \\
Insulin & Yes & Yes & Yes & No \\
IGF-1 & Present in milk & Yes & Yes & No, KO \\
KGF & Present in milk & Yes & ND & No, KO \\
PGE & ND & Yes & ND & Yes \\
Polyamines & Present in milk & Yes & Yes & Yes \\
T-cells & Yes & Yes & ND & Nos, KO \\
TGF $\alpha$ & Present in milk & Yes & Variable & Yes, KO \\
Thyroxine & Yes & Yes & & \\
\hline
\end{tabular}

*Corticosteroids do not promote expression of sucrase and other brush border genes in humans but they do induce expression in laboratory animals. They do not cause proliferation in human explant culture and are antitrophic to both the suckling and adult rat intestine.

TGLP-2 receptors are mainly distributed in the distal small intestine and colon.

$¥$ Some of the actions of thyroxine are mediated via corticosteroids.

$\S$ Knockout animals have generally only been examined for major abnormalities of intestinal and other organ development and not the small intestine morphometrically

EGF, epidermal growth factor; Epo, erythropoietin; bFGF, fibroblast basic growth factor; GH, growth hormone; GLP, glucagon-like polypeptide; HGF, hepatocyte growth factor; IGF-1, insulin-like growth factor 1 ; $\mathrm{KGF}$, keratinocyte growth factor; $\mathrm{PGE}_{2}$, prostaglandin $\mathrm{E}_{2} ; \mathrm{TGF}$, transforming growth factor; $\mathrm{KO}$, knockout mouse; ND, not determined; Yes, has been determined.

whether growth factors may unphysiologically activate some receptors on the basolateral surface of crypt enterocytes to promote crypt hyperplasia.

Another way to investigate the physiological relevance of growth factors is to assess which growth factors are present in breast milk (table 1). Some specific growth factors that are present in breast milk are $\mathrm{EGF},{ }^{25} \mathrm{Epo},{ }^{26}$ basic fibroblast growth factor, ${ }^{27} \mathrm{HGF}^{28}{ }^{29}$ IGF-1, and IGF-II, ${ }^{27}$ while TGF- $\beta$ may have a negative growth effect. ${ }^{30-32}$ No single milk borne growth factor has been established as mediating intestinal growth; more than one factor may be involved or others may act at different tissue (mucosa, submucosa, muscle) levels of the intestine.

\section{EPITHELIAL GROWTH OF THE SMALL INTESTINE DURING WEANING}

Epithelial growth with crypt hyperplasia and expansion of the secondary mucosal surface

Weaning is the gradual process of replacement of milk feeding with an increasing range of ingested nutrients. The diet changes from a high fat and low carbohydrate in breast milk to a low fat and high carbohydrate diet. We found that infants have a median duration of breast feeding of 4.2 months. ${ }^{33}$ Median ages of introduction of liquid and solid feed supplements were 1.7 and 4.0 months, respectively. ${ }^{33}$ Thus human infants typically wean with liquid and solid feed supplements introduced from two and four months of age, respectively, although breast feeding is commonly recommended for six months.

"Studies in both laboratory rats and human infants have shown that weaning is associated with accelerated epithelial growth with villous and crypt hyperplasia"

Studies in both laboratory rats and human infants have shown that weaning is associated with accelerated epithelial growth with villous and crypt hyperplasia. ${ }^{34-38}$ In human infants, crypt length and crypt cell proliferation are $31 \%$ and $68 \%$ higher, respectively, than values for adult subjects (fig 4 ). It is difficult to compare mucosal growth from birth in humans, as unlike laboratory animals, no quantitative data of intestinal structure from neonates are available to serve as a reference for comparison with older infants and children. However, the morphological description of narrow finger-like villi and small crypts in neonates suggest that villus area is perhaps one third to one half that of infants during weaning. This is because the width of villi increases more than the length postnatally, as they become leaf-like within one month of birth. ${ }^{128}$ This villous and crypt hyperplasia expands the secondary mucosal surface area in preparation for the nutrient load with weaning (fig 4). Villi amplify the basic cylindrical lining (the primary surface area) of the small intestine by fourfold in the proximal jejunum and by twofold in the ileum in adults. ${ }^{39} 40$

Controversy still exists about whether these epithelial changes are intrinsically programmed or induced by luminal food and other factors that occur at weaning. The fact that delayed weaning does not abrogate intestinal growth has been taken as evidence of intrinsic programming ${ }^{41}{ }^{42}$ but this did not take into account intestinal growth by crypt fission. Other studies have shown that precocious weaning in animals accelerates villous and crypt hyperplasia, ${ }^{43} 44$ which argues that luminal factors modulate intestinal growth.

\section{Assessment of growth factors for the small intestine during weaning}

One approach in assessing the role of growth factors of the small intestine has been to study luminal survival, intestinal absorption, and systemic uptake of pharmacological doses of potential growth factors such as EGF or IGF- $1 .{ }^{45}$ Growth factors were assessed in vitro or in vivo but usually in pharmacological doses (table 1). Different methods of assessing intestinal growth have been used, such as intestinal wet or dry 


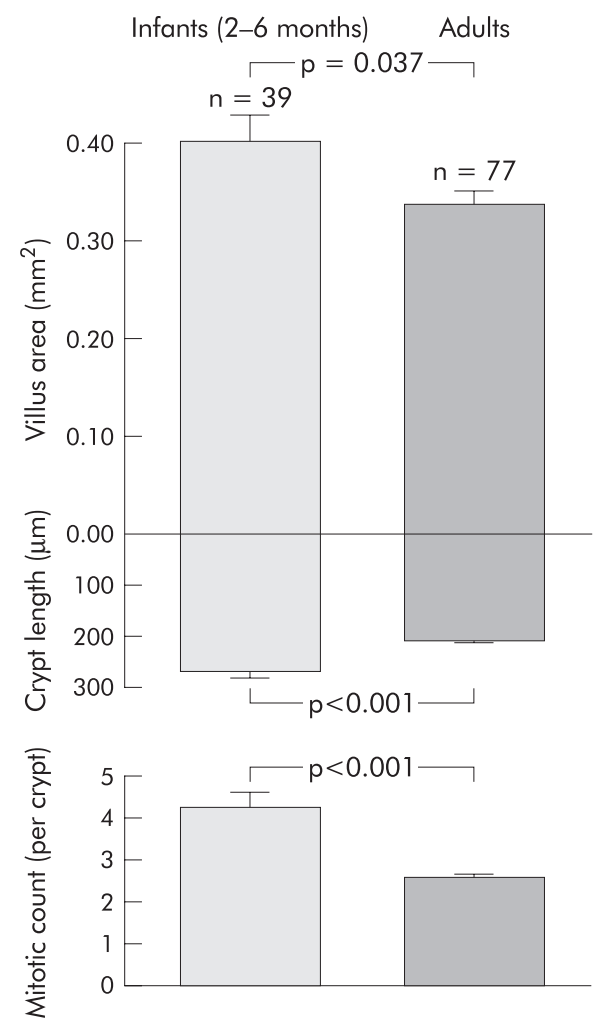

Figure 4 Villus area, crypt length, and crypt cell proliferation (mitotic count per crypt) in human infants compared with adult subjects. Graphs were drawn from a study by Thompson and colleagues. ${ }^{38}$

weight, weight of mucosal scrapping, protein or DNA content of mucosal scrapping, functional changes such as in alkaline phosphatase or disaccharidase activity, intestinal morphology, and intestinal morphometry. Intestinal morphometry has the advantage that it measures villus surface area (which correlates with the number of villus enterocytes), crypt length (which correlates with the number of crypt enterocytes), and percentage of bifid crypts and crypt mitotic count (these measure crypt fission and crypt hyperplasia, respectively). ${ }^{46} \mathrm{It}$ is still not widely acknowledged that villi grow both in length and width (that is, surface area) but crypts mainly grow in length, and that villus length alone is a poor measure of growth. ${ }^{47}$ Another method of measuring villus area and mucosal surface area is by cycloid stereology which can be used on conventional histological sections but has the disadvantage that crypt size and cell proliferation are not measured. ${ }^{48}{ }^{49}$

The criteria for identification of physiological growth factors for intestinal growth have been discussed by Vanderhoof ${ }^{50}$ and by Henning and colleagues. ${ }^{51}$ We propose the following principal criteria:

- to demonstrate the presence of the growth factor in breast milk or its expression in the intestinal mucosa at the time of growth;

- to demonstrate the presence and activation of the growth factor receptor at the time of growth;

- to demonstrate reduction of growth in vivo with removal of the relevant growth factor by ablation, by blockade of the growth factor or its receptor, or by otherwise inducing loss of function (knockout mouse).

Supporting minor criteria which may help in selecting a suitable growth factor to investigate would be:
- to demonstrate that early administration in doses approximating the physiological range should induce precocious growth;

- to study the effect of the growth factor in vitro.

\section{Corticosteroids}

The effect of corticosteroids on inducing alkaline phosphatase, sucrase, and other brush border enzymes in rodents has been extensively studied for many decades. ${ }^{52-54}$ Corticosteroids are present in breast milk but also circulate systemically in infants. In humans, sucrase, isomaltase, and trehalase in humans are expressed early from about 9-10 weeks of fetal life and reach $70-100 \%$ of adult levels (except for lactase which increases later) by 14 weeks of gestation. ${ }^{55}$ These changes predate the systemic peak of circulating corticosteroids in late pregnancy. In addition, corticosteroids have no effect in inducing disaccharidases in human fetal explant culture of small intestine. ${ }^{56}$

"The effects of corticosteroids on cellular proliferation in the small intestine are conflicting"

The effects of corticosteroids on cellular proliferation in the small intestine are conflicting with one study indicating increased proliferation ${ }^{36}$ and others showing reduced crypt cell proliferation in human fetal explant culture, and in infant and adult rodents. ${ }^{42} 5657$ The report of increased proliferation could be explained by a rebound effect after corticosteroid treatment. It has also been shown in several intestinal epithelial cell lines that corticosteroids arrest growth and downregulate cell cycle regulatory proteins. ${ }^{58}$ Thus corticosteroids are not a specific growth factor for the small intestine in humans.

\section{Epidermal growth factor and transforming growth factor $\alpha$}

EGF and TGF- $\alpha$ are two of many ligands of the EGF receptor and have been proposed as important growth factors in breast milk for the postnatal small intestine. EGF is present in breast milk at $25-40 \mathrm{ng} / \mathrm{ml}$ in colostrum and $5-12 \mathrm{ng} / \mathrm{ml}$ in mature milk. EGF promotes growth of the small intestine in vitro ${ }^{59}$ and in vivo when given in pharmacological but not in physiological doses to rats. ${ }^{25}{ }^{60}$ Systemic administration of EGF in an infant had a modest effect in enhancing intestinal growth, as demonstrated morphometrically. ${ }^{16}$ TGF- $\alpha$ is also present in human breast milk at $2-7 \mathrm{ng} / \mathrm{ml}$ but at a $5-10$-fold lower concentration than EGF. ${ }^{61}$ Triple null knockout mice for EGF, TGF- $\alpha$, and amphiregulin have duodenal lesions and disturbed ileum architecture but apparently intact jejunal growth. ${ }^{62}$

"EGF and TGF- $\alpha$ are two of many ligands of the EGF receptor and have been proposed as important growth factors in breast milk for the postnatal small intestine"

What argues against EGF and TGF- $\alpha$ as being principally important growth factors is the evidence that EGF receptors have low expression during milk feeding and delayed expression until weaning, at least in rodents. ${ }^{63}$ EGF receptor knockout mice have phenotypes that vary from no apparent effect on intestinal development to shortened villi. ${ }^{64-66}$

\section{Erythropoietin}

Recent evidence suggests that Epo may be a growth factor for the neonatal small intestine. Epo is present in breast milk at $11 \mathrm{mU} / \mathrm{ml}^{26}$ and Epo receptors are expressed on intestinal cells. ${ }^{67}$ Juul et al have shown that recombinant human Epo given enterally or systemically by subcutaneous injection to artificially fed rat pups modestly lengthened the small intestine and increased villus surface area. ${ }^{68}$ Moreover, rat pups suckled on dams treated intraperitoneally with Epo for 
1-2 weeks had $9 \%$ longer length of the small intestine and a $15 \%$ increase in villus surface area ${ }^{68}$ Unlike other growth factors, Epo did not lead to precocious maturation as sucrase activity remained low. These studies are intriguing but mitigated by the modest increments of growth observed. It would be important in future studies to investigate whether Epo induces crypt fission.

\section{Hepatocyte growth factor}

The concentration of HGF in colostrum and mature milk is 2.2 and $1.8 \mathrm{ng} / \mathrm{ml}$, respectively. ${ }^{29} \mathrm{C}$-met, a proto-oncogene and the HGF receptor, is present on intestinal crypt epithelial cells although it is also expressed in the muscle layers of the intestine. ${ }^{69}$ HGF and c-met mRNA are expressed in fetal ${ }^{69} 70$ and adult intestinal tissue ${ }^{71}$ but no study has investigated to what extent HGF is produced endogenously in the postnatal small intestine. We have preliminary evidence that HGF has low expression in the neonatal human ileum (as assessed by relative polymerase chain reaction for mRNA) but that the mucosa and crypt enterocytes have increased c-met mRNA and protein expression compared with adult subjects (unpublished data). Thus HGF in breast milk, but not produced endogenously, is available to interact with c-met to induce a response. HGF stimulates intestinal IEC-6, Caco-2, and T84 epithelial cells, and rat fetal intestinal cells in primary culture. $^{28} 7273$ HGF induces intestinal growth in rats when administered in pharmacological doses. ${ }^{74}$ Thus HGF is a growth factor that is present in breast milk and whose c-met receptor is expressed by intestinal crypt cells in the postnatal period of life. The c-met receptor responds with phosphorylation on engagement of HGF. ${ }^{69}{ }^{76}$ What still has not been shown is whether physiological blockade of $\mathrm{HGF}$ or of c-met decreases intestinal growth, particularly crypt fission.

\section{Insulin-like growth factor 1}

IGF-1 is present in breast milk and is also produced endogenously in the neonatal mucosa. The concentration of IGF- 1 in colostrum is $10 \mathrm{ng} / \mathrm{ml}$ and in mature milk ranges from 2 to $19 \mathrm{ng} / \mathrm{ml}^{77}$ It has been suggested as a primary growth factor of the small intestine but this evidence is mostly based on either cell culture ${ }^{78}$ or pharmacological infusion in rats. ${ }^{790}$ IGF-1 receptors are expressed in the small intestine but are predominantly localised to the submucosa and muscle layers. ${ }^{81}{ }^{82}$ IGF-1 receptor binding or immunostaining is lowest in the duodenum and increases distally, ${ }^{82-84}$ but intestinal growth with suckling is predominantly in the proximal small intestine. ${ }^{20}$ In the pig, mucosal levels of IGF-1 were low in 0,3 , and 5 day old animals whereas numbers of IGF-1 receptors were highest on day 0 , suggesting that the physiological source of IGF-1 is in breast milk and may only be active for a few days postnatally. ${ }^{85}$

"IGF-1 may be more important in intestinal muscle growth especially of the distal small and large intestines"

The IGF-1 transgenic mouse overexpresses mRNA for IGF-1 by 20-30-fold and this causes intestinal growth, particularly of the muscle layers, ${ }^{86}$ which agrees with IGF-l receptor localisation. IGF-1 also induces regrowth of the distal rather than proximal small intestine after methotrexate induced damage. ${ }^{87}$ Thus IGF-1 may be more important in intestinal muscle growth especially of the distal small and large intestines, even though at pharmacological doses it causes mucosal growth.

\section{Glucagon-like polypeptide 2}

A systemic action of enteroglucagon causing intestinal crypt hyperplasia was first observed clinically. ${ }^{88}$ GLP-2 is a 33 amino acid fragment of the larger proglucagon molecule and is released by enteroendocrine cells of the ileum in response to nutrient ingestion. The GLP-2 receptor is predominantly distributed to the hypothalamus, stomach, and small and large intestines. ${ }^{89} 90$ GLP-2 has multiple actions including inducing intestinal crypt hyperplasia, reducing apoptosis, inhibiting gastric emptying, and regulating appetite and food intake. It is regarded as having a relatively gastrointestinal specific action compared with other growth factors. Serum levels of GLP-2 and intestinal expression of mRNA for GLP-2 receptors both peak during breast feeding (days 1 and 12) and decline to adult levels after weaning in rats. ${ }^{90}$ The ontogeny of serum GLP-2 levels and of intestinal expression of GLP-2 receptors in human infants have not been reported.

\section{Transforming growth factor $\beta$}

Several studies have shown that TGF- $\beta$ reduces intestinal proliferation in intestinal cell lines. ${ }^{30-32}$ TGF- $\beta$ exists in different isoforms with TGF- $\beta 2$ being the only isoform in rat milk, ${ }^{91}$ but both TGF- $\beta 1$ and 2 are present in human milk. ${ }^{92}$ Penttila et al have shown that, as TGF- $\beta 2$ concentration declines in breast milk of the rat, TGF- $\beta 1$ expression is induced in the weaning epithelium and that this is associated with loss of the TGF- $\beta 3$ receptor, making the mucosa progressively unresponsive to TGF- $\beta 2$ in breast milk. ${ }^{91}$ Thus TGF- $\beta 2$ in breast milk may relatively inhibit crypt hyperplasia until weaning. What still needs to be established is whether TGF- $\beta 2$ affects crypt fission (presumably it does not do so) and whether TGF- $\beta$ reduces crypt hyperplasia in vivo.

\section{Activated T cells}

Our studies have been directed at the hypothesis that intestinal growth during weaning is a consequence of physiological inflammation. ${ }^{63}$ There are several lines of evidence to support this notion. Firstly, mast cell degranulation and activity of $\mathrm{T}$ cells peak at mid weaning in laboratory rats ${ }^{93-95}$ and in healthy human infants. ${ }^{33}{ }^{38}$ Secondly, this activity is localised to the gut associated lymphoid tissue with a peak of interleukin $2 \mathrm{R}$ in mesenteric lymph nodes, Peyer's patches, and lamina propria in laboratory rats at weaning. ${ }^{95}$ The proinflammatory cytokines interleukin $1 \beta$ and tumour necrosis factor $\alpha$ also peak in the jejunum during weaning in the rat. ${ }^{97}{ }^{98}$ Thirdly, intestinal crypt hyperplasia is known to be T cell dependent, although the action is likely indirect. ${ }^{69} 100$ This indirect action could be explained by T cells activating mesenchymal cells, in particular pericryptal fibroblasts, to produce growth factors. Finally, immunosuppression with cyclosporin A or with antibody blockade of interleukin $2 \mathrm{R}$ retards intestinal growth at weaning. ${ }^{95} 97$

\section{Keratinocyte growth factor}

One mesenchymal growth factor that is produced by immunologically activated fibroblasts is KGF, which is upregulated in the intestine from patients with inflammatory bowel disease.$^{101-103}$ In addition, KGF promotes proliferation in vitro of the rat IEC-6 intestinal cell line ${ }^{104}$ and fetal human small intestine in explant culture. ${ }^{105}$ It also promotes in vivo growth and proliferation of the small intestine when given systemically to rats. ${ }^{106} \mathrm{KGF}$ receptor is expressed by both intestinal crypts and villi. ${ }^{105} \mathrm{KGF}$ is the only growth factor that upregulates sucrase expression in fetal explant culture of the small intestine whereas EGF reduces sucrase expression; Epo, HGF, corticosteroids, and insulin have no effect. ${ }^{68}{ }^{105}$ It remains to be shown whether KGF is a physiological growth factor during weaning

\section{IMPORTANCE OF UNDERSTANDING INTESTINAL GROWTH}

The question arises as to what is the importance of understanding the physiology of intestinal growth? It is important to understand normal growth to select possible 
growth factors that could be used therapeutically in short bowel syndrome. A cautionary tale already exists for growth hormone therapy which increased mortality in critically ill adults and has been associated with cardiomyopathy when used to treat short bowel syndrome in children. ${ }^{107}$ The same caution would apply to IGF-1 therapy. A way of overcoming these complications could be treatment by local gene therapy, as has been demonstrated with replacement of lactase expression in the rat. ${ }^{108}$ Short bowel syndrome may require sequential treatment with appropriate growth factors for age.

"It is important to understand normal growth to select possible growth factors that could be used therapeutically in short bowel syndrome"

Cylindrical organ growth in the neonate and infant requires a growth factor that predominantly induces crypt fission to expand the primary mucosal surface. It is not really necessary, or physiologically appropriate, to induce villous hyperplasia especially if breast feeding continues or if expressed breast milk is gavaged.

\section{FUTURE DIRECTIONS}

Further research work is needed, particularly examination of intestinal tissue from humans given the continuing difficulty in extrapolating results from laboratory animals. This should be possible using material from surgical trimming or biopsies taken at endoscopy. It is important that quantitative histological techniques be used to define intestinal growth and that crypt fission and crypt hyperplasia should be distinguished. What remains to be resolved is whether there is a single predominant growth factor for crypt fission and another (presumably) for crypt hyperplasia or whether multiple growth factors induce growth.

\section{ACKNOWLEDGEMENTS}

We are grateful for the assistance and cooperation of Associate Professor Geoff Davidson, Dr Richard Couper, Dr David Moore, and Dr Paul Hammond and other staff in the Centre for Paediatric and Adolescent Gastroenterology at the Women's and Children's Hospital, Adelaide, for continuing collaboration. Some of the work described was funded from grants from the Channel 7 Research Foundation of South Australia and the Nutricia Research Foundation (the Netherlands).

This review is based on a Lecture given at the Tenth Annual Postgraduate Course in Paediatric Gastroenterology, Royal Free Hospital, London, UK, December 1999.

\section{Authors' affiliations}

A G Cummins, F M Thompson, Bazil Hetzel Research Institute and the Department of Gastroenterology and Hepatology, The Queen Elizabeth Hospital, Adelaide, South Australia, Australia

\section{REFERENCES}

1 Grand R, Watkins J, Torti F. Development of the human gastrointestinal tract. A review. Gastroenterology 1976;70:790-810.

2 Klein RM, MacKenzie JC. The role of cell renewal in the ontogeny of the intestine. I. Cell proliferation patterns in adult, fetal and neonatal intestine. J Pediatr Gastroenterol Nutr 1983;2:10-43.

3 Klein R, MacKenzie J. The role of cell renewal in the ontogeny of the intestine. II. Regulation of cell proliferation in adult, fetal and neonatal intestine. J Pediatr Gastroenterol Nutr 1983;2:204-28.

4 Henning SJ. Functional development of the gastrointestinal tract. In: Johnson SJ, ed. Physiology of the gastrointestinal tract. New York: Raven Press, 1987:285-300.

5 Ménard D. Growth-promoting factors and the development of the human gut. In: Lebenthal E, ed. Human gastrointestinal development. New York: Raven Press, 1989:123-50

6 Marsh MN, Cummins AG. The interactive role of mucosal T lymphocytes in intestinal growth, development and enteropathy. J Gastroenterol Hepatol 1993;8:270-8

7 Moxley P, Trier J. Development of villus absorptive cells in the human fetal intestine: a morphological and morphometric study. Anat Rec 1979; 195:463-82.

8 Walker-Smith JA. Small bowel morphology in childhood. Med J Aust 1969;1:382-7.
9 Walker-Smith JA. Variation of small intestinal morphology with age. Arch Dis Child 1972:47:80-3.

10 Stenling R, Fredrikzon B, Nyhlin $\mathrm{H}$, et al. Surface ultrastructure of the small intestine mucosa in healthy children and adults: a scaning electron microscope study with some methodological aspects. Ultra Pathol 1984;6:131-40

11 Baker SJ, Ignatius M, Mathan VI, et al. Intestinal biopsy. In: Wolstenholme GEW, Cameron MP, eds. Intestinal biopsy. Boston: Little, Brown and Co, 1962:84-102.

12 Chacko CJG, Paulson KA, Mathan VI, et al. The villus architecture of the small intestine in the tropics: a necropsy study. J Pathol 1969:98:146-56.

13 Cook GC, Kajubi SK, Lee FD. Jejunal morphology of the African in Uganda. J Pathol 1969;98:157-69.

14 Clarke RM. The effect of growth and of fasting on the number of villi and crypts in the small intestine of the albino rat. J Anat 1972;112:27-33.

15 St Clair WH, Osborne JW. Crypt fission and crypt number in the small and large bowel of postnatal rat. Cell Tissue Kinet 1985;18:255-62.

16 Sullivan PB, Brueton M, Tabara ZB, et al. Epidermal growth factor in necrotising enteritis. Lancet $1991 ; 338: 54-3$

17 Park H-S, Goodlad RA, Ahnen DJ, et al. Effects of epidermal growth factor and dimethyhydrazine on crypt size, cell proliferation, and crypt fission in the rat colon. Am J Pathol 1997; 151:843-52

18 Playford RJ, Marchbank T, Mandir N, et al. Effects of keratinocyte growth factor (KGF) on gut growth and repair. J Pathol 1998; 184:316-22

19 Thompson JS, Saxena SK, Sharp JG. Difluoromethylornithine inhibits crypt fission. J Gastrointest Surg 1999;3:662-7.

20 Widdowson EM, Colombo VE, Artavams CA. Changes in the organs of pigs in response to feeding for the first 24 hours after birth. Biol Neonate 1976;28:272-81

21 Heird WC, Hansen IH. Effect of colostrum on growth of intestinal mucosa. Pediatr Res 1977:11:406A.

22 Hall RA, Widdowson EM. Response of the organs of rabbits to feeding during the first days of birth. Biol Neonate 1979;35:131-9.

23 Schwartz SM, Heird WC. Further studies of colostrum-stimulated enteric mucosal growth. Pediatr Res 1981;15:A546.

24 Yamashiro Y, Sato M, Shimizu T, et al. Possible biological growth factors in beast milk and postnatal development of the gastrointestinal tract. Acta Paediatr Jpn 1989;31:417-23.

25 Berseth CL. Enhancement of intestinal growth in neonatal rats by epidermal growth factor in milk. Am J Physiol 1987;253:G662-5.

26 Kling PJ, Sullivan TM, Roberts RA, et al. Human milk as a potential enteral source of erythropoietin. Pediatr Res 1998:43:216-21.

27 Schams D. Growth factors in milk. Endocr Regul 1994;28:3-8.

28 Fukamachi $\mathbf{H}$, Ichinose M, Tsukada S, et al. Hepatocyte growth factor region specifically stimulates gastro-intestinal epithelial growth in primary culture. Biochem Biophys Res Comm 1994;205:1445-51.

29 Yamade Y, Saito S, Morikawa H. Hepatocyte growth factor in human breast milk. Am J Reprod Immunol 1998;40:112-20.

30 Koyama S-Y, Podolsky DK. Differential expression of transforming growth factors $\alpha$ and $\beta$ in rat intestinal epithelial cells. J Clin Invest 1989;83:1768-73.

31 Halttunen T, Marttinen A, Rantala I, et al. Fibroblasts and transforming growth factor beta induce organization and differentiation of T84 human epithelial cells. Gastroenterology 1996;111:1252-62.

32 Murphy MS. Growth factors and the gastrointestinal tract. Nutrition 1998; 14:771-4.

33 Cummins AG, Eglinton BA, Gonsalez A, et al. Immune activation during infancy in healthy humans. J Clin Immunol 1994;14:107-15.

34 Koldovsky O, Sunshine P, Kretchmer N. Cellular migration of intestinal epithelia in suckling and weaned rats. Nature 1966;212:1389-90.

35 Hruby L. A quantitative study of the relative growth of the small intestine of the rat during the period of suckling. Folia Morphol 1966;15:308-14.

36 Herbst JJ, Sunshine P. Postnatal development of the small intestine of the rat. Changes in mucosal morphology at weaning. Pediatr Res 1969;3:27-33

37 Yeh K-Y. Cell kinetics in the small intestine of suckling rats. Anat Rec 1977; 188:338-47.

38 Thompson FM, Catto-Smith AG, Moore D, et al. Epithelial growth of the small intestine in human infants. J Pediatr Gastroenterol Nutr 1998;26:506-12

39 Wilson JP. Surface area of the small intestine in man. Gut 1967:8:618-21.

40 Moog F. The lining of the small intestine. Sci Am 1981;245:116-25.

41 Lebenthal E, Sunshine P, Kretchmer N. Effect of prolonged nursing on the activity of intestinal lactase in rats. Gastroenterology 1973;62:1136-41.

42 Buts J-P, De Meyer R. Intestinal development in the suckling rat: effects of weaning, diet composition, and glucocorticoids on thymidine kinase activity and DNA synthesis. Pediatr Res 1984:18:145-50.

43 Lee PC, Lebenthal E. Early weaning and precocious development of small intestine in rats: genetic, dietary or hormonal control. Pediatr Res 1983; 17:645-50.

44 Kanno T, Koyanagi N, Katoku Y, et al. Simplified preparation of a refined milk formula comparable to rat's milk: influence of the formula on development of the gut and brain in artifically reared rat pups. J Pediatr Gastroenterol Nutr 1997;3:242-52

45 Koldovsky $\mathrm{O}$. Search for role of milk-borne biologically active peptides for the suckling. J Nutr 1989;119:1543-51.

46 Hasan M, Ferguson A. Measurements of intestinal villi in non-specific and ulcer-associated duodenitis between area of microdissected villus and villus epithelial cell number. J Clin Pathol 1981;34:1181-6. 
47 Cummins AG, LaBrooy JT, Stanley DP, et al. Quantitative histological study of enteropathy associated with HIV infection. Gut 1990;31:317-21.

48 Baddeley AJ, Gundersen HJG, Cruz-Orive LM. Estimation of surface area from vertical sections. J Microsc 1986;142:259-76.

49 Langberg CW, Saver T, Reitan JB, et al. Relationship between intestinal fibrosis and histopathologic and morphometric changes in consequential and late radiation enteropathy. Acta Oncol 1996;35:81-7.

50 Vanderhoof JA. Editorial. Regulatory peptides and intestinal growth. Gastroenterology 1993;104:1205-8.

51 Henning SJ, Rubin DC, Shulman RJ. Ontogeny of the intestinal mucosa. In: Johnson L, ed. Physiology of the gastrointestinal tract. New York: Raven Press, 1994:571-610.

52 Moog F. The functional differentation of the small intestine. III. Influence of the pituitary-adrenal system in the differentiation of phosphatases in the duodenum of the suckling mouse. J Exp Zool 1953;124:329-46.

53 Doell RG, Kretchmer N. Intestinal invertase: precocious development of activity after injection of hydrocortisone. Science 1964;143:1608-21.

54 Polk DB, Barnard JA. Hormones and growth factors in intestinal development. In: Sanderson IR Walker WA, eds. Development of the gastrointestinal tract. Hamilton: BC Decker Inc, 2000:37-55

55 Antonowicz I, Lebenthal E. Developmental pattern of small intestinal enterokinase and disaccharidase activities in the human fetus. Gastroenterology 1977;72:1299-303.

56 Arsenaud P, Ménard D. Influence of hydrocortisone on human fetal small intestine in organ culture. J Pediatr Gastroenterol Nutr 1985;4:893-901.

57 Wright NA, Al-Dewachi HS, Appleton DR, et al. The effect of single and multiple doses of prednisolone tertiary buty acetate on cell population kinetics in the small bowel mucosa of the rat. Virchows Arch (Cell Pathol) 1978;28:339-50.

58 Quaroni A, Tian JQ, Göke M, et al. Glucocorticoids have pleiotropic effects on small intestinal crypt cells. Am J Physiol 1999;277:G1027-40.

59 Ichiba H, Kusuda S, Itagane $Y$, et al. Measurement of growth promoting activity in human milk using a fetal small intestinal cell line. Biol Neonate 1992;61:47-53

60 Pollack PF, Goda T, Colony PC, et al. Effects of enterally fed epidermal growth factor on the small and large intestine of the suckling rat. Regul Pept 1987; 17:121-32.

61 Okada M, Okimura E, Kamiya Y, et al. Transforming growth factor (TGF)- $\alpha$ in human milk. Life Sci 1991;48:1151-6.

62 Troyer KL, Luetteke NC, Saxon ML, et al. Growth retardation, duodenal lesions, and aberrant ileum architecture in triple null mice lacking EGF, amphireulin, and TGF- $\alpha$. Gastroenterology 2001;121:68-78

63 Gallo-Payet N, Pothier P, Hugon JS. Ontogeny of EGF receptors during postnatal development of mouse small intestine. J Pediatr Gastroenterol Nutr 1987:6: 1 14-20.

64 Miettinen PJ, Berger JE, Meneses J, et al. Epithelial immaturity and multiorgan failure in mice lacking epidermal growth factor receptor Nature 1995;376:337-41.

65 Sibilia M, Wagner EF. Strain-dependent epithelial defects in mice lacking the EGF receptor. Science 1995;269:234-8.

66 Threadgill DW, Dlugosz AA, Hansen LA, et al. Targeted disruption of mouse EGF receptor: effect of genetic background on mutant phenotype. Science 1995;269:230-4

67 Juul SE, Joyce A, Zhao Y, et al. Why is erythropoietin present in human milk? Studies of erythropoietin receptors on enterocytes of human and rat neonates. Pediatr Res 1999:46:263-8.

68 Juul SE, Ledbetter DJ, Joyce AE, et al. Erythropoietin acts as a trophic factor in neonatal rat intestine. Gut 2001;49:182-9.

69 Kermorgant S, Walker F, Hormi K, et al. Developmental expression and functionality of hepatocyte growth factor and c-met in human fetal digestive tissues. Gastroenterology 1997; 112:1635-47.

70 Wang Y, Selden C, Farnaud S, et al. Hepatocyte growth factor (HGF/SF) is expressed in human epithelial cells during embryonic development; studies by in situ hydridisation and Northern blot analysis. J Anat 1994; 185:543-51.

71 Wolf HK, Zamegar R, Rahija R, et al. Localization of hepatocyte growth factor in human and rat tissues: an immunohistochemical study. Hepatology 1991;14:488-94.

72 Dignass A, Lynch-Devaney K, Podolsky D. Hepatocyte growth factor/scatter factor modulates intestinal epithelial proliferation and migration. Biochem Biophys Res Commun 1994;202:701-9.

73 Göke M, Kanai M, Podolsky DK. Intestinal fibroblasts regulate intestinal epithelial proliferation via hepatocyte growth factor. Am J Physiol 1998;274:G809-18.

74 Kato Y, Yu D, Lukish JR, et al. Influence of luminal hepatocyte growth factor on small intestine mucosa in vivo. J Surg Res 1997;71:49-53.

75 Kato Y, Yu D, Lukish JR, et al. Hepatocyte growth factor enhances intestinal mucosal cell function and mass in vivo. J Pediatr Surg 1997;32:991-4.

76 Birchmeier C, Sonnenberg E, Weidner KM, et al. Tyrosine kinase receptors in the control of epithelial growth and morphogenesis during development. Bio Essays 1993;15:185-90.

77 Lönnerdal B, Adkins Y. Developmental changes in breast milk protein composition during lactation. In: Sanderson IR Walker WA, eds. Development of the gastrointestinal tract. Hamilton: B C Decker Inc, 2000:227-44

78 MacDonald RG, McCusker RH, Blackwood DJ, et al. Production of insulin-like growth factor (IGF-1) and IGF-binding proteins by rat intestinal stromal cells in vitro. Cell Mol Life Sci 1998;54:158-66.

79 Steeb C-B, Trahair JF, Tomas FM, et al. Prolonged administration of IGF peptides enhances growth of gastrointestinal tissues in normal rats. Am J Physiol 1994;266:G1090-8.
80 Steeb CB, Trahair JF, Read LC. Administration of insulin-like growth factor-1 (IGF-1) peptides for three days stimulates proliferation of the small intestinal epithelium in rats. Gut 1995;37:630-8.

81 Young GP, Taranto TM, Jonas HA, et al. Insulin-like growth factors and the developing and mature rat small intestine: receptors and biological actions. Digestion 1990;46:240-52.

82 Heinz-Erian P, Kessler U, Funk B, et al. Identification and in situ localization of the insulin-like growth factor-11 mannose-6-phosphate (IGF-1 1/M6P) receptor in the rat gastrointestinal tract: comparison with the IGF-1 receptor. Endocrinology 1991;129:1769-78.

83 Buts JP, De Keyser N, Marandi S, et al. Expression of insulin receptors and of $60-\mathrm{kDa}$ receptor substrate in mature and immature enterocytes. Am J Physiol 1997;273:G217-26.

84 Ryan J, Costigan DC. Determination of the histological distribution of insulin-like growth factor I receptors in the rat gut. Gut 1993;34:1693-7.

85 Schober DA, Simmen FA, Hadsell DL, et al. Perinatal expression of type I GF-1 receptors in porcine small intestine. Endocrinology 1990; 126:1 125-32.

86 Wang J, Niu W, Nikiforov Y, et al. Targeted overexpression of IGF-1 evokes distinct patterns of organ remodelling in smooth muscle cell tissue beds of transgenic mice. J Clin Invest 1997; 1000:1425-39.

87 Howarth GS, Cool JC, Bourne AJ, et al. Insulin-like growth factor-1 (IGF-1) stimulates regrowth of the damage intestine in rats, when administered following, but not concurrent with, methotrexate. Growth Factors 1998;15:279-92.

88 Gleeson HM, Bloom SR, Polak JM, et al. Endocrine tumour in kidney affecting small bowel structure, motility, and absorptive function. Gut $1971 ; 12: 773-82$

89 Yusta B, Huang L, Munroe D, et al. Enterocrine localization of GLP-2 receptor expresson in humans and rodents. Gastroenterology 2000; 119:744-55

90 Lovshin J, Yusta B, lliopoulos I, et al. Ontogeny of the glucagon-like peptide-2 receptor axis in the developing rat intestine. Endocrinology 2000; 141:4194-201.

91 Penttila IA, van Spiel $A B$, Xian $C$, et al. Transforming growth factor- $\beta$ levels in maternal milk and expression in the postnatal rat duodenum and ileum. Pediatr Res 1998;44:524-31.

92 Saito $S$, Yoshida $M$, Ichijo $M$, et al. Transforming growth factor-beta (TGF $\beta$ ) in human milk. Clin Exp Immunol 1993;94:220-4.

93 Cummins AG, Steele TW, LaBrooy JT, et al. Maturation of the rat small intestine at weaning: changes in epithelial cell kinetics, bacterial flora and mucosal immune activity. Gut 1988;29:1672-9.

94 Cummins AG, Munro GH, Miller HRP, et al. Association of maturation of the small intestine at weaning with mucosal mast cell activation in the rat. Immunol Cell Biol 1988;66:417-22.

95 Thompson FM, Mayrhofer G, Cummins AG. Dependence of epithelia growth of the small intestine on T cell activation during weaning in the rat. Gastroenterology 1996;111:37-44.

96 Masiedi $M$, Thompson FM, Tivey D, et al. Activation of the gut-associated lymphoid tissue with expression of interleukin-2 receptors that peaks during weaning in the rat. J Pediatr Gastroenterol Nutr 1999;29:556-62

97 Mengheri E, Ciapponi L, Vignolini F, et al. Cytokine gene expression in intestine of rat during the postnatal development period: increased IL-1 expression at weaning. Life Sci 1996;59:1227-36.

98 Schaeffer C, Diab-Assef M, Plateroti $M$, et al. Cytokine gene expression during postnatal small intestinal development: regulation by glucocorticoids. Gut 2000:47: 192-9.

99 Ferguson A, Jarrett EEE. Hypersensitivity reactions in the small intestine. I. Thymus dependency of experimental 'partial villous atrophy'. Gut 1975;16:114-17.

100 MacDonald TT, Bajaj-Elliott M, Pender SLF. T cells orchestrate intestinal mucosal shape and integrity. Immunol Today 1999;20:505-10.

101 Bajaj-Elliott M, Bresse EJ, Poulsom R, et al. Increased expression of keratinocyte growth factor (KGF) in inflammatory bowel disease (IBD). Possible role in epithelial restitution after tissue injury. Immunol Cell Biol 1997;75:A113.

102 Bajaj-Elliott $M$, Breese $E$, Poulson R, et al. Keratinocyte growth factor in inflammatory bowel disease. Increased mRNA transcripts in ulcerative colitis compared with Crohn's disease in biopsies and isolated mucosa myofibroblasts. Am J Pathol 1997;151:1469-76.

103 Bajaj-Elliott M, Poulson R, Pender SLF, et al. Interactions between stromal cell-derived keratinocyte growth factor and epithelial transforming growth factor in immune-mediated crypt cell hyperplasia. J Clin Invest 1998; 102:1473-80.

104 Dignass AU, Tsunekawa S, Podolsky DK. Fibroblast growth factors modulate intestinal epithelial cell growth and migration. Gastroenterology 1994; 106:1254-62.

105 Chaillier P, Basque J-P, Corriveau L, et al. Functional characterization of the keratinocyte growth factor system in human fetal gastrointestinal tract. Pediatr Res 2000;48:504-10

106 Housely RM, Morris CF, Boyle W, et al. Keratinocyte growth factor induces proliferation of hepatocytes and epithelial cells throughout the rat gastrointestinal tract. J Clin Invest 1994:94:1764-77.

107 Takala J, Ruokonen E, Webster NR, et al. Increased mortality associated with growth and growth hormone treatment in critically ill adults. N Engl J Med 1999;341:785-92.

108 During MJ, Xu R, Young D, et al. Peroral gene therapy of lactose intolerance using an adenovirus-associated virus vector. Nat Med 1998;4:1131-5. 